\title{
CAPÍTULO 27: OTIMIZAÇÃO DO MEIO DE CULTURA PARA A PRODUÇÃO DE UM COMPLEXO ENZIMÁTICO A PARTIR DE CASCA DE Mangifera indica L. (MANGA) POR FERMENTAÇÃO SÓLIDA
}

\author{
CHAPTER 27: OPTIMIZATION OF THE CULTURE MEDIA FOR THE \\ PRODUCTION OF ENZYMATIC COMPLEX FROM THE SHELL OF Mangifera \\ indica L. (MANGA) UNDER SOLID FERMENTATION
}

Sergio Luis Yupanqui Mendoza ${ }^{1}$; Ángel Pablo Castro Alvarado²; Gracinda Marina Castelo da Silva ${ }^{3}$

\section{Resumo}

Os componentes do meio de cultura para a produção de um extrato enzimático, a partir da fermentação em substrato sólido de cascas de manga por Aspergillus niger ATCC 9642, foram otimizados utilizando um Delineamento Composto Central Rotacional (DCCR). Os resultados obtidos com a metodologia Plackett-Burman, indicaram que das cinco variáveis estudadas, apenas três (peptona, extrato de levedura e pectina cítrica) foram consideradas significativas $(\mathrm{p}<0,05)$ para a produção enzimática. A otimização das três variáveis foi realizada através do método DCCR, cobrindo um total de 18 unidades experimentais, incluindo quatro pontos centrais. A atividade enzimática máxima apresentada para a celulase total foi de $0,819 \mathrm{U} / \mathrm{g}$, de 26,97 U/g para a endoglucanase (CMCase) e de 129,86 U/g para a pectinase, valores experimentais obtidos quando se utilizou um meio sólido otimizado composto por: casca de manga suplementado com peptona $5,5 \mathrm{~g} / \mathrm{L}$, extrato de levedura $6,84 \mathrm{~g} / \mathrm{L}$ e pectina cítrica 6,94 $\mathrm{g} / \mathrm{L}$. Os testes de validação dos modelos polinomiais apresentaram um relacionamento adequado entre os valores previstos e experimentais, para as atividades enzimáticas FPase, CMCase e pectinase.

Palavras-Chaves: Extrato enzimático, fermentação em substrato sólido, cascas de manga, otimização.

\begin{abstract}
The components of the culture medium for the production of enzymatic extract, from fermentation in solid substrate of mango peels by Aspergillus niger ATCC 9642, were optimized using a Central Rotational Compound Design (DCCR). The results obtained with the Plackett-Burman methodology, indicated that of the five variables studied, only three (peptone, yeast extract and citrus pectin) were considered significant $(p<0,05)$ for enzyme production. The optimization of the three variables was performed using the DCCR, covering a total of 18 experimental units, including four central points. The maximum enzymatic activity presented for total cellulase was $0,819 \mathrm{U} / \mathrm{g}$, for endoglucanase (CMCase) of $26,97 \mathrm{U} / \mathrm{g}$ and pectinase activity of $129,86 \mathrm{U} / \mathrm{g}$, experimental values that were obtained when using a solid medium optimized composed of mango peel supplemented with $5,5 \mathrm{~g} / \mathrm{L}$ peptone, $6,84 \mathrm{~g} / \mathrm{L}$ yeast extract and $6,94 \mathrm{~g} / \mathrm{L}$ citrus pectin. The validation tests of the polynomial models showed an adequate relationship between the predicted and experimental values, for the enzymatic activities FPase, CMCase and pectinase.
\end{abstract}

Keywords: Enzymatic extract, solid-state fermentation, mango peels, optimization.

\footnotetext{
1 Programa de Pós-graduação em Processos Químicos e Biotecnológicos (PPGQB), Universidade Tecnológica Federal do Paraná, Brasil, sergioluis@ alunos.utfpr.edu.br

2 Programa de Graduación en Biotecnología, Universidad Nacional del Santa, Perú, aca1castro@ gmail.com

${ }^{3}$ Doutora em Engenharia Química, Universidade Tecnológica Federal do Paraná, Brasil, gmarina@utfpr.edu.br
} 


\section{Introdução}

$\mathrm{O}$ aumento da demanda por produtos agroindustriais aumenta exponencialmente conforme o crescimento da população. Satisfazer a demanda leva a uma maior produção de produtos alimentícios, resultando em um alto nível de resíduos. O acúmulo desses resíduos não apenas representa um problema ambiental, mas também resulta em perda de material potencialmente valioso devido à variabilidade de sua composição estrutural, destacando seu alto valor nutricional (MUÑOZ; PANTOJA; CUATIN, 2014). Tendo em conta a necessidade de administrar a enorme quantidade de resíduos agroindustriais produzidos e agregando a ele seu baixo custo, alta disponibilidade e alto valor nutricional, aumentou-se o interesse em seu uso em processos biotecnológicos (MOJUMDAR; DEKA, 2019).

A biotecnologia aplicada ao uso de material agroindustrial tem sido responsável por reescrever o que é geralmente conhecido por "desperdício", para matérias-primas, formando e desenvolvendo outros produtos (SADH; DUHAN; DUHAN, 2018). Dessa forma, a disponibilidade desses nutrientes em matérias-primas agroindustriais oferece ambientes adequados para o crescimento de microrganismos.

A manga é uma das principais frutas produzidas no Brasil e detém o título da fruta com maior valor nas exportações brasileiras (ANUÁRIO BRASILEIRO DE HORTI\&FRUTI, 2019). O resíduo da industrialização da manga é constituído principalmente por casca e semente, representando entre $40 \%$ a $60 \%$ da fruta (MUÑOZ; PANTOJA; CUATIN, 2014). Sua importante fonte de carboidratos, proteínas, pectinas, fibras e componentes minerais levou esses resíduos a serem candidatos a substratos para a produção de enzimas hidrolíticas por fermentação sólida (Vários).

O grupo de enzimas celulase e pectinases está dentro do grupo enzimático mais amplamente utilizado comercialmente. Ambos os complexos podem ser sintetizados extracelularmente via fermentação por uma ampla variedade de fungos filamentosos, entre os quais as cepas de Aspergillus niger apresentaram rendimentos mais elevados (MRUDULA; MURUGAMMAL, 2011).

Em suma, é importante estabelecer condições de fermentação que maximizem a produção enzimática, para isso, vários meios de cultura são utilizados para suprir as necessidades nutricionais dos microrganismos. Por sua vez, o complexo enzimático produzido deve apresentar um equilíbrio adequado de atividade entre as diferentes enzimas celulolíticas que agem sinergicamente em conjunto com as enzimas pectinolíticas. Assim, o presente trabalho tem como objetivo otimizar o meio de cultura para a produção de um complexo enzimático por Aspergillus niger ATCC 9642 em meio de fermentação sólido, utilizando casca de manga como principal fonte de carbono e energia. 


\section{Material e Métodos}

\section{Microrganismo}

O microrganismo utilizado para a fermentação foi uma linhagem de Aspergillus niger ATCC 9642, pertencente à coleção do Laboratório de Biotecnologia Marinha do "Centro de Investigación Científica y de Educación Superior de Ensenada" (CICESE), Baja California, México. Os esporos de manutenção do fungo filamentoso foram preservados em tubos com tampa de rosca, em solução estéril e armazenados a $-4{ }^{\circ} \mathrm{C}$. A ativação dos esporos foi realizada utilizando a metodologia proposta por Rodríguez-Zúñiga et al., (2011), com algumas modificações em duas etapas de transferência. Inicialmente, os esporos foram transferidos para um meio básico formulado por Couri e Farias (1995), com a seguinte composição (g/L): Pectina cítrica (10,0), NaNO3 (3,0), KH2PO4 (1,0), MgSO4.7H2O (0,5), KCl (0,5), FeSO4.7H2O $(0,01)$, ágar-ágar (20,0), pH do meio ajustado em 4,2 e incubado por 5 dias a $30^{\circ} \mathrm{C}$. Os conídios crescidos foram suspensos em $10 \mathrm{~mL}$ de solução estéril de Tween 80 estéril a $0,1 \%$ (p/v).

A segunda etapa de transferência consistiu em inocular $1 \mathrm{~mL}$ de conídios suspensos em solução estéril em um Erlenmeyer de $250 \mathrm{~mL}$ contendo $5 \mathrm{~g}$ de casca de manga estéril e prétratada, ajustando a umidade com água destilada a $70 \%$, com $\mathrm{pH}$ de 4,5 a $32{ }^{\circ} \mathrm{C}$ por 5 dias, período em que a formação micelial fúngica foi verificada. Para obter a solução de inoculação, $100 \mathrm{~mL}$ de solução de surfactante estéril Tween 80 a $0,1 \%(\mathrm{p} / \mathrm{v})$ foram adicionados ao frasco Erlenmeyer contendo os esporos crescentes na casca de manga. A suspensão de esporos foi separada das partículas de casca de manga por filtração com gaze. A concentração final de inóculo para todas as fermentações realizadas foi de $10^{7}$ esporos por grama de substrato sólido, sendo determinada por meio de uma câmara de Neubauer.

\section{Substrato e condições de pré-tratamento}

Os resíduos de casca de manga da variedade Kent foram gentilmente doados pela empresa "Inversiones Frigoríficas PRC S.A." localizado na cidade de Santa, Áncash, Peru.

Com o objetivo de aumentar a biodisponibilidade de estruturas celulósicas das cascas de manga nas fermentações sólidas, foi realizado um tratamento térmico com água fervente. Primordialmente, as cascas de manga foram cortadas em tamanho uniforme de aproximadamente $10 \mathrm{~cm}$ e, em seguida, tratadas com água destilada em ebulição, seguindo o método descrito por Mostafa et al., (2013). Para aumentar a área de ação enzimática, as fibras de casca de manga tratadas foram esmagadas em um moinho de facas e peneiradas, até atingir um tamanho de partícula de $0,5 \mathrm{~mm}$. As porcentagens de massa seca de lignina, celulose, hemicelulose e pectina foram estimadas antes e após o tratamento. 


\section{Condições de fermentação e extração enzimática}

Os meios de fermentação sólidos para a produção de enzimas foram preparados seguindo a metodologia proposta por Rodríguez-Zúñiga et al., (2011), apresentando algumas modificações. Foram utilizados frascos Erlenmeyer de $250 \mathrm{~mL}$ aos quais foram adicionados 5 g de casca de manga pré-tratada. O meio basal descrito por Mandels e Weber (1969), foi utilizado para todas as fermentações sólidas, variando apenas as concentrações de peptona, uréia, extrato de levedura (NH4)2SO4 e pectina cítrica para indução de atividade enzimática, a formulação dos meios foi realizado seguindo o delineamento experimental Plackett-Burman. As condições fermentativas foram realizadas com temperatura de $32{ }^{\circ} \mathrm{C}, \mathrm{pH}$ em 4,5 , ajustando a porcentagem de umidade para $70 \%$ com água destilada suplementada com nutrientes (concentrações de acordo com o delineamento experimental). Os frascos Erlenmeyer foram finalmente esterilizados a $121{ }^{\circ} \mathrm{C}, 1 \mathrm{~atm}$ por $30 \mathrm{~min}$.

A extração enzimática foi realizada seguindo a metodologia proposta por Mrudula e Murugammal (2011). O extrato enzimático foi extraído do meio sólido misturando homogeneamente todo o meio de fermentação com água destilada (1:10 p/v) e agitada em um agitador rotativo $(120 \mathrm{rpm})$ a $30{ }^{\circ} \mathrm{C}$ com um tempo de contato de 1 hora. Utilizou-se um tecido gaze umedecido para filtrar os extratos para depois ser centrifugados a $6000 \mathrm{rpm}$ por $15 \mathrm{~min}$, o sobrenadante claro foi usado como fonte de enzima extracelular.

\section{Determinação da atividade enzimática}

A atividade da endoglucanase ou carboximetilcelulase (CMCase) foi determinada medindo espectrofotometricamente os açúcares redutores produzidos a partir de $2 \%(\mathrm{p} / \mathrm{v})$ de carboximetilcelulose, enquanto a atividade celulase total-teste de papel de filtro (FPase) foi determinada pela estimativa dos açúcares redutores liberados durante a degradação do papel de filtro Whatman $\mathrm{N}^{\circ} 1(1,0 \times 6,0 \mathrm{~cm})($ WOOD; BHAT, 1988). O método do ácido dinitrosalicílico (DNS) foi utilizado para quantificação da atividade enzimática. Os ensaios de reação foram realizados incorporando $0,5 \mathrm{~mL}$ de tampão de citrato de sódio $50 \mathrm{mM}$ ( $\mathrm{pH} 4,8$ ), extrato enzimático de $0,5 \mathrm{~mL}$ e $0,5 \mathrm{~mL}$ de carboximetilcelulose ( $2 \%$ em volume) em um tubo de ensaio. A reação de controle negativo não continha CMC e o branco continha $0,5 \mathrm{~mL}$ de DNS e 0,5 $\mathrm{mL}$ de tampão de citrato de sódio. Para a atividade FPase, $1 \mathrm{~mL}$ de tampão de citrato de sódio $50 \mathrm{mM}(\mathrm{pH} 4,8), 0,5 \mathrm{~mL}$ de extrato enzimático e uma tira de papel de filtro foram adicionados a um tubo. $\mathrm{O}$ controle negativo continha $1,5 \mathrm{~mL}$ de tampão e uma tira de papel de filtro e o branco continha $0,5 \mathrm{~mL}$ de tampão e $0,5 \mathrm{~mL}$ de DNS. O tempo de reação foi de 10 min para CMCase e FPase, que então foram incubadas a $50{ }^{\circ} \mathrm{C}$. As amostras foram diluídas com a adição de $10 \mathrm{~mL}$ de agua destilada para medições de absorbância a $540 \mathrm{~nm}$. Uma unidade de atividade 
MENDOZA, S. L. Y., ALVARADO, A. P. C. E SILVA, G. M. C.

da CMCase ou FPase (U) é definida como $1 \mu \mathrm{mol}$ de açúcar redutor liberado por minuto de reação. Entretanto, a medição da atividade da pectinase foi realizada utilizando pectina cítrica (pectina 0,5\% em tampão citrato de sódio $0,05 \mathrm{M}, \mathrm{pH} 4,8$ ), nas mesmas condições supracitadas. Uma unidade de atividade enzimática pectinase foi definida como a quantidade de enzima que libera $1 \mu \mathrm{mol}$ de açúcares redutores (como ácido galacturônico) por minuto de reação.

\section{Delineamento Experimental}

\section{Metodologia Plackett-Burman}

A triagem dos componentes do meio de fermentação e seus efeitos sobre a atividade enzimática foram determinados por meio do delineamento experimental Placket-Burman, utilizando o software Statistica versão 10.0 (StatSoft Inc. 2010, EUA). O delineamento experimental consiste no uso de dois níveis, que localizam variáveis significativas ao rastrear as variáveis "n" nos experimentos "n + 1" (KARLAPUDI et al., 2018).

Testou-se cinco fatores (listados na Tabela 1), obtendo-se um conjunto de oito experimentos (Tabela 2). Cabe mencionar que todos os experimentos foram realizados em triplicata. $\mathrm{O}$ efeito principal foi calculado basicamente como uma diferença entre as medições médias de cada variável realizada em um nível alto $(+1)$ e baixo $(-1)$, selecionando as variáveis em um modelo de primeira ordem, como mostra a equação 1.

$Y=\beta_{0}+\sum \beta_{i} x_{i}$

onde $Y$ foi a resposta (atividade enzimática), $\beta_{0}$ foi o intercepto do modelo, $\beta_{i}$ é o coeficiente de regressão e $x_{i}$ é a variável independente.

A análise estatística do modelo foi realizada para o cálculo da análise de variância (ANOVA), considerando que os fatores com nível de significância de $5 \%(\mathrm{p}<0,05)$ tiveram efeito significativo no meio de fermentação para produção de enzimas. 
MENDOZA, S. L. Y., ALVARADO, A. P. C. E SILVA, G. M. C.

Tabela 1. Valores e níveis das variáveis do planejamento Plackett-Burman

\begin{tabular}{lllll}
\hline $\begin{array}{l}\text { Delineamento Variáveis } \\
\text { experimental }\end{array}$ & & & Concentração $(\mathrm{g} / \mathrm{L})$ \\
\cline { 1 - 2 } & & -1 & +1 \\
\hline & Peptona $\left(\mathrm{X}_{1}\right)$ & 0.75 & 6,00 \\
& Extrato de levedura $\left(\mathrm{X}_{2}\right)$ & 0,25 & 6,00 \\
& Ureia $\left(\mathrm{X}_{3}\right)$ & 0,3 & 3,00
\end{tabular}

Plackett-Burman

$\begin{array}{lll}(\mathrm{NH} 4) 2 \mathrm{SO} 4\left(\mathrm{X}_{4}\right) & 1,4 & 3,00 \\ \text { Pectina cítrica }\left(\mathrm{X}_{5}\right) & 1,00 & 5,00\end{array}$

Fonte: Própria (2020).

\section{Delineamento Composto Central Rotacional}

Após a seleção das variáveis, o DCCR foi utilizado para otimizar a atividade enzimática do extrato produzido. Foi realizado um planejamento fatorial $2^{3}$, incluindo seis pontos axiais, oito pontos fatoriais e quatro pontos centrais, obtendo um número total de 18 unidades experimentais. Após a medição das respostas, cada uma foi ajustada a um modelo polinomial independente de segunda ordem, que foi usado para representar graficamente as superfícies de resposta, como mostra a equação 2 .

$Y=\beta_{0}+\sum \beta_{i} x_{i}+\sum \beta_{i j} x_{i} x_{j}+\sum \beta_{i i} x_{i}^{2}$

onde $\mathrm{Y}$ é o valor de resposta previsto (atividade enzimática otimizada), $\beta_{0}$ é o coeficiente de termo constante, $\beta_{i}$ é o coeficiente de efeito linear, $\beta_{i i}$ é o coeficiente de efeito quadrático, $\beta_{i j}$ é o coeficiente de interação dos efeitos, $x_{i}$ e $x_{j}$ são os níveis codificado das variáveis $X_{i}$ e $X_{j}$. A relação entre $x_{i}$ e o valor verdadeiro da variável independente $X_{i}$ é a seguinte:

$x_{i}=\frac{X_{i}-X_{0}}{\Delta X_{i}}$

onde $X_{0}$ é o valor real da variável independente no ponto central do teste e $\Delta X_{i}$ é a mudança de etapa da variável independente.

A Tabela 2 representa os níveis das variáveis independentes utilizadas na experimentação. As variáveis dependentes (respostas) foram as atividades enzimáticas de celulase (CMCase e FPase) e pectinase, expressas em unidades enzimáticas por grama de substrato sólido utilizado (U/g). 
MENDOZA, S. L. Y., ALVARADO, A. P. C. E SILVA, G. M. C.

Tabela 2. Valores e níveis das variáveis do Delineamento Composto Central Rotacional (DCCR)

\begin{tabular}{|c|c|c|c|c|c|c|}
\hline \multirow{2}{*}{$\begin{array}{l}\text { Delineamento } \\
\text { experimental }\end{array}$} & \multirow[t]{2}{*}{ Variáveis } & \multicolumn{5}{|c|}{ Concentração (g/L) } \\
\hline & & $-1,682$ & -1 & 0 & +1 & $+1,682$ \\
\hline & Peptona $\left(\mathrm{X}_{1}\right)$ & 2,136 & 3.50 & 5,50 & 7,50 & 8,864 \\
\hline & Extrato de levedura $\left(\mathrm{X}_{2}\right)$ & 0,995 & 3,00 & 6,00 & 9,00 & 11,045 \\
\hline
\end{tabular}

DCCR

Pectina cítrica $\left(\mathrm{X}_{3}\right) \quad 4,136 \quad 5,5 \quad 7,5 \quad 9,5 \quad 10,864$

Fonte: Própria (2020).

\section{Resultados e Discussão}

\section{Seleção das variáveis significativas}

A Tabela 3 representa a matriz experimental para o planejamento Plackett-Burman para a seleção de variáveis significativas no processo de fermentação sólida. Foi realizado um total de oito ensaios, utilizando um total de cinco variáveis independentes, representadas em valores reais e valores codificados. Foi possível observar um máximo de atividade enzimática para FPase (0,367 U/g), CMCase (11,758 U/g) e Pectinase (84 U/g), empregando um meio sólido suplementado com nutrientes, de acordo com a seguinte composição: peptona 6,00 g/L, extrato de levedura 6,00 g/L, ureia 3,00 g/L, $\left(\mathrm{NH}_{4}\right)_{2} \mathrm{SO}_{4} 3,00 \mathrm{~g} / \mathrm{L}$ e pectina cítrica em 5,00 g/L.

De acordo com a análise de variância ANOVA (dados não mostrados) e o gráfico de Pareto para a atividade celulase total (FPase), conforme representado na Figura 1.A, todas as variáveis estudadas apresentaram efeitos positivos. No entanto, apenas o extrato de levedura e peptona foram significativas $(\mathrm{p}<0,05)$.

Da mesma forma, para a análise da atividade da Carboximetilcelulase (CMCase), como mostra o gráfico de Pareto na Figura 1.B, três variáveis foram significativas, dentre elas o extrato de levedura, pectina cítrica e peptona $(\mathrm{p}<0,05)$, todas apresentando efeitos positivos para a fermentação.

Finalmente, a atividade enzimática pectinase apresentou duas variáveis significativas (Figura 1.C), pectina cítrica e extrato de levedura, ambas variáveis com efeitos positivos. Dessa forma, três nutrientes foram selecionados como variáveis independentes (peptona, extrato de levedura e pectina cítrica), para fins de otimização, utilizando as variáveis significativas no meio de fermentação para complementar os requisitos nutricionais das três atividades enzimáticas. 
MENDOZA, S. L. Y., ALVARADO, A. P. C. E SILVA, G. M. C.

Tabela 3. Delineamento experimental Plackett-Burman com as cinco variáveis em estudo e as atividades enzimáticas para FPase, CMCase e Pectinase.

\begin{tabular}{|c|c|c|c|c|c|c|c|c|c|c|c|c|c|}
\hline \multirow[t]{2}{*}{$\overline{\text { Ensaio }}$} & \multicolumn{2}{|c|}{ Peptona } & \multicolumn{2}{|c|}{$\begin{array}{r}\text { Extrato de } \\
\text { levedura }\end{array}$} & \multicolumn{2}{|c|}{ Ureia } & \multicolumn{2}{|c|}{$\left(\mathrm{NH}_{4}\right)_{2} \mathrm{SO}_{4}$} & \multicolumn{2}{|c|}{$\begin{array}{l}\text { ?ectina } \\
\text { cítrica }\end{array}$} & \multirow{2}{*}{$\begin{array}{l}\text { FPase } \\
\text { U/g }\end{array}$} & \multirow{2}{*}{$\begin{array}{l}\text { CMCase } \\
\mathrm{U} / \mathrm{g}\end{array}$} & \multirow{2}{*}{$\begin{array}{l}\text { Pectinase } \\
\mathrm{U} / \mathrm{g}\end{array}$} \\
\hline & $\begin{array}{c}\mathrm{X}_{1} \\
(\mathrm{~g} / \mathrm{L})\end{array}$ & $\mathrm{X} 1$ & $\begin{array}{c}\mathrm{X}_{2} \\
(\mathrm{~g} / \mathrm{L})\end{array}$ & $\mathrm{x}_{2}$ & $\begin{array}{c}\mathrm{X}_{3} \\
(\mathrm{~g} / \mathrm{L})\end{array}$ & $\mathrm{x}_{3}$ & $\begin{array}{c}\mathrm{X}_{4} \\
(\mathrm{~g} / \mathrm{L})\end{array}$ & $\mathrm{X}_{4}$ & $\begin{array}{c}\mathrm{X}_{5} \\
(\mathrm{~g} / \mathrm{L})\end{array}$ & $\mathrm{X}_{5}$ & & & \\
\hline 1 & 0,75 & -1 & 0,25 & -1 & 0,3 & -1 & 3,0 & 1 & 5,0 & 1 & 0,021 & 3,996 & 55,320 \\
\hline 2 & 6,0 & 1 & 0,25 & -1 & 0,3 & -1 & 1,4 & -1 & 1,0 & -1 & 0,112 & 4,097 & 35,190 \\
\hline 3 & 0,75 & -1 & 6,0 & 1 & 0,3 & -1 & 1,4 & -1 & 5,0 & 1 & 0,198 & 9,129 & 70,346 \\
\hline 4 & 6,0 & 1 & 6,0 & 1 & 0,3 & -1 & 3,0 & 1 & 1,0 & -1 & 0,324 & 8,836 & 49,080 \\
\hline 5 & 0,75 & -1 & 0,25 & -1 & 3,0 & 1 & 3,0 & 1 & 1,0 & -1 & 0,098 & 1,931 & 15,759 \\
\hline 6 & 6,0 & 1 & 0,25 & -1 & 3,0 & 1 & 1,4 & -1 & 5,0 & 1 & 0,175 & 7,418 & 65,070 \\
\hline 7 & 0,75 & -1 & 6,0 & 1 & 3,0 & 1 & 1,4 & -1 & 1,0 & -1 & 0,216 & 5,719 & 42,129 \\
\hline 8 & 6,0 & 1 & 6,0 & 1 & 3,0 & 1 & 3,0 & 1 & 5,0 & 1 & 0,367 & 11,758 & 84,635 \\
\hline
\end{tabular}

Fonte: Própria (2020). 
MENDOZA, S. L. Y., ALVARADO, A. P. C. E SILVA, G. M. C.

Figura 1. Gráficos de Pareto das variáveis significativas do meio de cultura da fermentação sólida. (A) Atividade celulase total (FPase), (B) Atividade endoglucanase (CMCase) e (C)

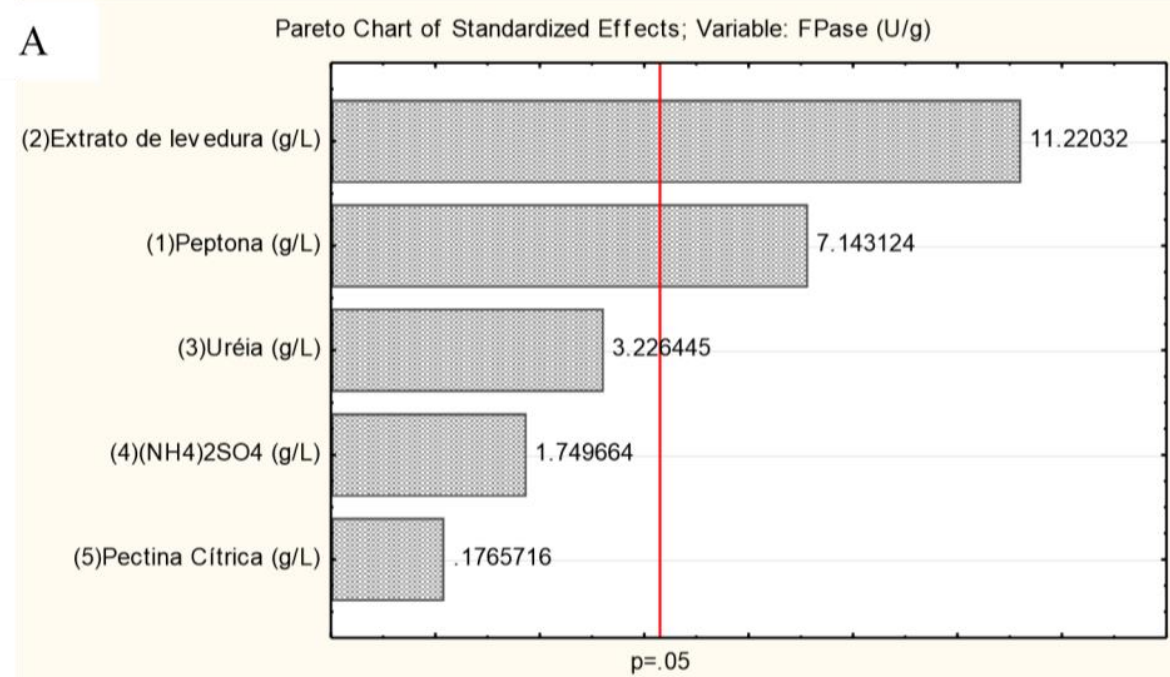

B
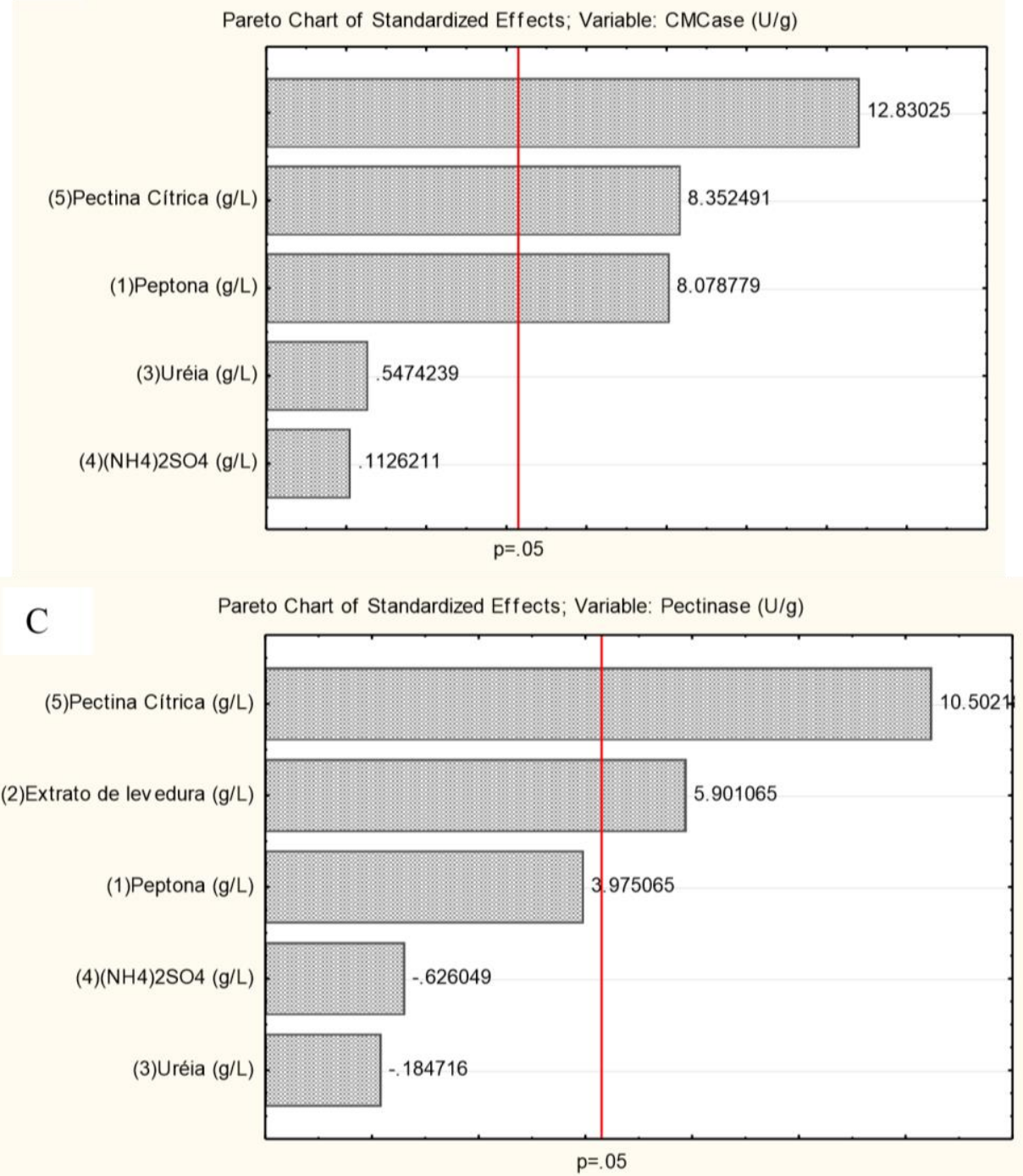

Fonte: Própria (2020). 
MENDOZA, S. L. Y., ALVARADO, A. P. C. E SILVA, G. M. C.

\section{Otimização do meio de cultura}

Foi realizado um DCCR, a fim de otimizar os componentes do meio fermentativo sólido e determinar seu efeito na atividade enzimática celulase (CMCase e FPase) e pectinase do extrato produzido por Aspergillus niger ATTC 9642.

Os experimentos realizados foram planejados com o objetivo de obter modelos quadráticos capazes de descrever o comportamento da enzima produzida no meio sólido de fermentação sob diferentes concentrações de nutrientes.

Nesse contexto, a matriz do DCCR $2^{3}$ (valores reais e codificados das concentrações de peptona, extrato de levedura e pectina cítrica) e os resultados das atividades enzimáticas da enzima Carboximetilcelulase (CMCase), atividade celulase pape filtro (FPase) e Pectinase obtidas a partir da fermentação em estado sólido de Aspergillus niger ATCC 9642, são apresentadas na Tabela 4.

Tabela 4. Matriz DCCR com os três componentes do meio de cultura para otimização

\begin{tabular}{|c|c|c|c|c|c|c|c|c|c|}
\hline \multirow[t]{2}{*}{ Ensaio } & \multicolumn{2}{|c|}{ Peptona } & \multicolumn{2}{|c|}{ Extrato de levedura } & \multicolumn{2}{|c|}{ Pectina cítrica } & \multirow{2}{*}{$\begin{array}{l}\text { FPase } \\
\text { U/g }\end{array}$} & \multirow{2}{*}{$\begin{array}{l}\text { CMCase } \\
\text { U/g }\end{array}$} & \multirow{2}{*}{$\begin{array}{c}\text { Pectinase } \\
\text { U/g }\end{array}$} \\
\hline & $\begin{array}{c}X_{1} \\
(g / L)\end{array}$ & $\mathbf{x}_{1}$ & $\mathrm{X}_{2}(\mathrm{~g} / \mathrm{L})$ & $\mathbf{x}_{2}$ & $\begin{array}{c}\mathrm{X}_{3} \\
(\mathrm{~g} / \mathrm{L})\end{array}$ & $\mathbf{x} 3$ & & & \\
\hline 1 & 3.5 & -1 & 3,0 & -1 & 5,5 & -1 & 0.457 & 17.685 & 79.145 \\
\hline 2 & 3.5 & -1 & 3,0 & -1 & 9,5 & 1 & 0.351 & 11.171 & 45.089 \\
\hline 3 & 3.5 & -1 & 9,0 & 1 & 5,5 & -1 & 0.653 & 21.092 & 123.109 \\
\hline 4 & 3.5 & -1 & 9,0 & 1 & 9,5 & 1 & 0.487 & 19.057 & 80.990 \\
\hline 5 & 7.5 & 1 & 3,0 & -1 & 5,5 & -1 & 0.591 & 18.321 & 105.214 \\
\hline 6 & 7.5 & 1 & 3,0 & -1 & 9,5 & 1 & 0.501 & 14.450 & 73.891 \\
\hline 7 & 7.5 & 1 & 9,0 & 1 & 5,5 & -1 & 0.621 & 20.478 & 88.053 \\
\hline 8 & 7.5 & 1 & 9,0 & 1 & 9,5 & 1 & 0.559 & 17.994 & 65.879 \\
\hline 9 & 2.136 & -1.682 & 6,0 & 0 & 7,5 & 0 & 0.457 & 14.256 & 87.210 \\
\hline 10 & 8.864 & 1.682 & 6,0 & 0 & 7,5 & 0 & 0.521 & 16.767 & 111.073 \\
\hline 11 & 5.5 & 0 & 0,955 & -1.682 & 7,5 & 0 & 0.411 & 14.012 & 55.391 \\
\hline 12 & 5.5 & 0 & 11,045 & 1.682 & 7,5 & 0 & 0.522 & 17.980 & 76.904 \\
\hline 13 & 5.5 & 0 & 6,0 & 0 & 4,136 & -1.682 & 0.759 & 23.890 & 95.008 \\
\hline 14 & 5.5 & 0 & 6,0 & 0 & 10,864 & 1.682 & 0.587 & 15.761 & 80.095 \\
\hline 15 & 5.5 & 0 & 6,0 & 0 & 7,5 & 0 & 0.795 & 25.017 & 119.908 \\
\hline 16 & 5.5 & 0 & 6,0 & 0 & 7,5 & 0 & 0.808 & 25.129 & 120.108 \\
\hline 17 & 5.5 & 0 & 6,0 & 0 & 7,5 & 0 & 0.801 & 25.008 & 120.479 \\
\hline 18 & 5.5 & 0 & 6,0 & 0 & 7,5 & 0 & 0.805 & 24.908 & 121.660 \\
\hline
\end{tabular}


Foi possível determinar uma atividade enzimática máxima para carboximetilcelulase (CMCase), atividade de celulase total-ensaio com papel filtro (FPase) e pectinase de 0,808 U/g, $25,129 \mathrm{U} / \mathrm{g}, 123,109 \mathrm{U} / \mathrm{g}$, respectivamente.

Os modelos polinomiais de segunda ordem expressos pelas equações 4,5 e 6 , em que as variáveis $\left(\mathrm{x}_{1}, \mathrm{x}_{2}\right.$ e $\left.\mathrm{x}_{3}\right)$ assumiram seus valores codificados, representam a atividade enzimática FPase, CMCase e pectinase, respectivamente, dependendo da concentração de peptona ( $\left.\mathrm{x}_{1}\right)$, extrato de levedura $\left(\mathrm{x}_{2}\right)$ e pectina cítrica $\left(\mathrm{x}_{3}\right)$ no meio de fermentação sólido.

FPase $(U / g)=0,802+0,031 x_{1}-0,11 x_{1}^{2}+0,044 x_{2}-0,118 x_{2}^{2}-0,052 x_{3}-$ $0,045 x_{3}^{2}-0,03 x_{1} x_{2}+0,015 x_{1} x_{3}-0,004 x_{2} x_{3}$

CMCase $(U / g)=24,972+0,473 x_{1}-3,165 x_{1}^{2}+1,733 x_{2}-2,994 x_{2}^{2}-2,09 x_{3}-$ $1,64 x_{3}^{2}-0,69 x_{1} x_{2}+0,27 x_{1} x_{3}+0,73 x_{2} x_{3}$

Pectinase $(U / g)=120,51+3,28 x_{1}-7,44 x_{1}^{2}+6,65 x_{2}-19,10 x_{2}^{2}-11,33 x_{3}-$ $11,53 x_{3}^{2}-13,13 x_{1} x_{2}+2,83 x_{1} x_{3}+0,13 x_{2} x_{3}$

A análise de variância ANOVA foi realizada para validar estatisticamente os modelos polinomiais. A ANOVA para o modelo de segunda ordem referente à resposta da atividade da FPase (dados não apresentados), indicou que todos os efeitos lineares e quadráticos foram significativos, assim como a interação entre a concentração de peptona e o extrato de levedura $(p<0,05)$. As interações entre a concentração de peptona-pectina e extrato de levedura-pectina não apresentaram significância estatística. Da mesma forma, a análise de variância mostrou um $\mathrm{R}^{2}$ de 0,989 , ou seja, aproximadamente $98,9 \%$ da variação observada na atividade FPase, pode ser explicada pelo modelo ajustado expresso na Equação 4. Portanto, a validade do modelo pode ser afirmada para explicar o comportamento da variável dependente. Por sua vez, também foi determinado o $\mathrm{R}^{2}$ ajustado, cujo valor garante ou não um ajuste satisfatório do modelo polinomial de segunda ordem aos dados avaliados na experimentação. $\mathrm{O} \mathrm{R}^{2}$ ajustado para a atividade FPase foi 0,977 , valor numericamente semelhante ao $\mathrm{R}^{2}$ do modelo.

A ANOVA para o modelo de segunda ordem referente à resposta da atividade da carboximetilcelulose (CMCase) indicou que os efeitos lineares e quadráticos da concentração do extrato de levedura e pectina, bem como o efeito quadrático da concentração de peptona, foram significativos $(\mathrm{p}<0,05)$. $\mathrm{O}$ efeito das interações entre as variáveis (peptona-extrato de levedura, peptona-pectina cítrica e extrato de levedura-pectina cítrica), bem como o efeito linear da peptona não foram significativos. $\mathrm{O} \mathrm{R}^{2}$ do modelo foi de 0,973 , ou seja, aproximadamente 97,3\% da variação observada na atividade de carboximetilcelulase (CMCase), pode ser explicada pelo modelo ajustado expresso na Equação 5. Portanto, a validade do modelo pode 
ser usada para explicar o comportamento da variável dependente. $\mathrm{O} \mathrm{R}^{2}$ ajustado para a atividade CMCase foi 0,944 , numericamente similar ao $\mathrm{R}^{2}$ do modelo.

A análise ANOVA do último caso, correspondente à atividade da pectinase, mostrou que os efeitos linear e quadrático da concentração de extrato de levedura e pectina cítrica foram significativos, assim como o efeito quadrático da concentração de peptona e a interação entre a concentração do extrato de levedura e peptona $(\mathrm{p}<0,05)$. $O \mathrm{R}^{2}$ neste caso foi de 0,936 e o $\mathrm{R}^{2}$ ajustado de 0,864 ; sendo capaz de afirmar a validade do modelo para explicar o comportamento da atividade da pectinase.

O valor estatístico resultante da otimização do meio de cultura para a concentração de peptona foi de 5,5 g/L, extrato de levedura com 6,84 g/L e concentração de pectina cítrica em $6,93 \mathrm{~g} / \mathrm{L}$. Os valores previstos foram o resultado da análise estatística para um perfil de desejabilidade ideal das atividades enzimáticas em estudo; os valores das atividades enzimáticas previstas foram para atividade celulase total (FPase) de 0,808 U/g, atividade de endoglucanase ou carboximetilcelulase de $25.129 \mathrm{U} / \mathrm{g}$ e atividade de pectinase de $123,11 \mathrm{U} / \mathrm{g}$.

A otimização do meio de cultura mostrou que uma concentração moderada de fontes de nitrogênio (extrato de levedura e peptona) tem um efeito positivo na atividade celulase. Os efeitos quadráticos significativos das concentrações do meio para peptona, extrato de levedura e pectina cítrica mostraram uma região ótima para as três atividades enzimáticas em estudo (curvatura nas superfícies de resposta). O aumento da concentração de extrato de levedura em todas as fermentações significou uma diminuição da atividade enzimática, Infanzón-Rodríguez et al., (2020) afirmaram que um aumento excessivo na concentração de extrato de levedura, embora favorecesse o crescimento de fungos, diminui a atividade celulase.

Da mesma forma, o valor estatístico previsto na experimentação para o extrato de levedura (6,84 g/L) coincide com os resultados obtidos por Shahriarinour et al., (2011), nos quais determinou maior atividade enzimática da FPase e da CMCasa empregando um meio sólido suplementado com $6 \mathrm{~g} / \mathrm{L}$ de extrato de levedura.

O efeito da concentração de peptona foi semelhante ao efeito obtido com a suplementação do extrato de levedura, apresentando algumas modificações. O efeito quadrático da concentração de peptona no meio de fermentação sólido foi significativo para todas as atividades enzimáticas, ao contrário de seu efeito linear, o qual apenas teve um efeito significativo no cálculo da atividade celulase total (FPase). Pode-se afirmar que a concentração adequada de peptona em um meio de fermentação não deve estar fora da faixa de otimização estabelecida (5,5 g/L na experimentação). A peptona é considerada uma excelente fonte de nitrogênio para a produção de celulases, como o extrato de levedura, sendo considerada por 
alguns autores a principal fonte de nitrogênio na produção de enzimas celulases (GAUTAM et al., 2011; SHOUKRY; HASSAN; EL-SHALL, 2019).

A concentração de pectina no meio de cultura teve um efeito significativo na análise da atividade da celulase e pectinase. A enzima pectinase pode quebrar polímeros heterogêneos de hemicelulose que se interconectam com as microfibrilas de celulose (GUPTA et al., 2016). Portanto, isso explica o fato do trabalho sinérgico das enzimas celulases e pectinases no extrato enzimático produzido; para o benefício da hidrólise da celulose.

Assim, uma clara redução na atividade enzimática pectinase também foi evidenciada quando se utilizou meios de cultura com baixas concentrações de pectina, bem como uma clara melhoria na atividade enzimática ao trabalhar em altas concentrações das mesmas, isso pode explicar o caráter induzível das enzimas pectinases em diferentes concentrações de pectina (AHMED et al., 2016). Todavia, embora baixas concentrações de pectina produzam baixa atividade pectinase, na experimentação foi possível obter o contrário, dito de outro modo, utilizando o valor estatístico da concentração de pectina $(6,94 \mathrm{~g} / \mathrm{L})$ que se relaciona à porcentagem de pectina no meio de cultura sólido, valor moderadamente baixo; é possível obter como resultado uma alta atividade enzimática pectinase estimada em 123,11 U/g (valor estatístico previsto de acordo com o DCCR).

A atividade de pectinase apresentada, embora tenha um perfil induzido pela concentração de pectina, a contribuição da composição estrutural das cascas de manga foi uma vantagem considerável sobre a atividade enzimática. As cascas de manga são compostas por carotenoides, fibra dietética, polifenóis e pectina, sendo esta última considerada um dos principais constituintes estruturais da parede celular (15\% do peso seco da casca) e, por sua vez, reconhecida por diferentes autores por sua alta qualidade (BERARDINI et al., 2005).

A Figura 2 mostra os gráficos da superfície de resposta e os gráficos de contorno para a interação entre a concentração do extrato de levedura e peptona em resposta à atividade enzimática FPase, CMCase e pectinase. Os gráficos são representações das equações polinomiais de segundo grau mostradas nas equações 4,5 e 6. Pode-se observar que, todos os gráficos da superfície de resposta e os gráficos de contorno têm uma região com presença de curvatura ou superfície quadrática, que, como já foi definido, é a região onde apresenta uma maximização da resposta estudada. As demais interações resultantes do delineamento experimental não foram apresentadas neste estudo, porém apresentaram superfícies semelhantes. 
Figura 2. Gráficos de superfície de resposta e gráficas de contorno para a interação entre a concentração de peptona e o extrato de levedura em resposta à atividade enzimática. (A) Atividade celulase total (FPase), (B) atividade de endoglucanase (CMCase) e (C) atividade pectinase de Aspergillus niger ATCC 9642.

A Fitted Surface; Variable: FPase (U/g)
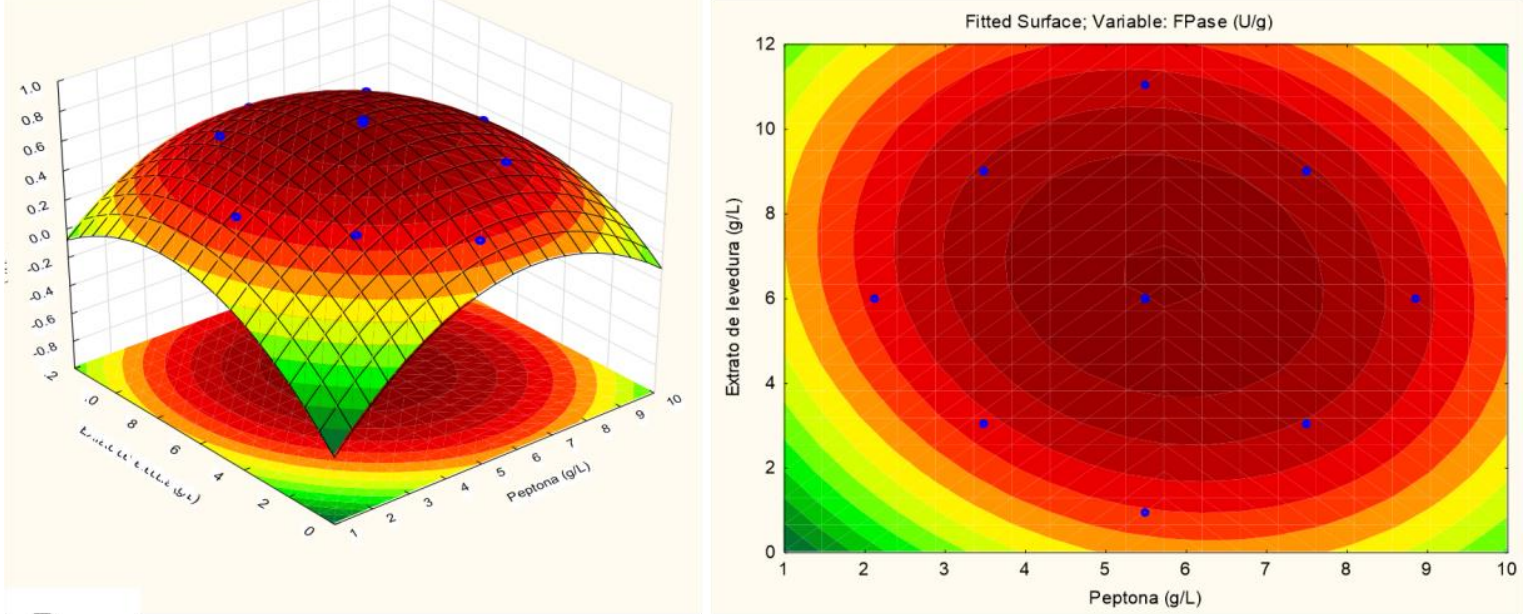

B

Fitted Surface; Variable: CMCase (U/g)
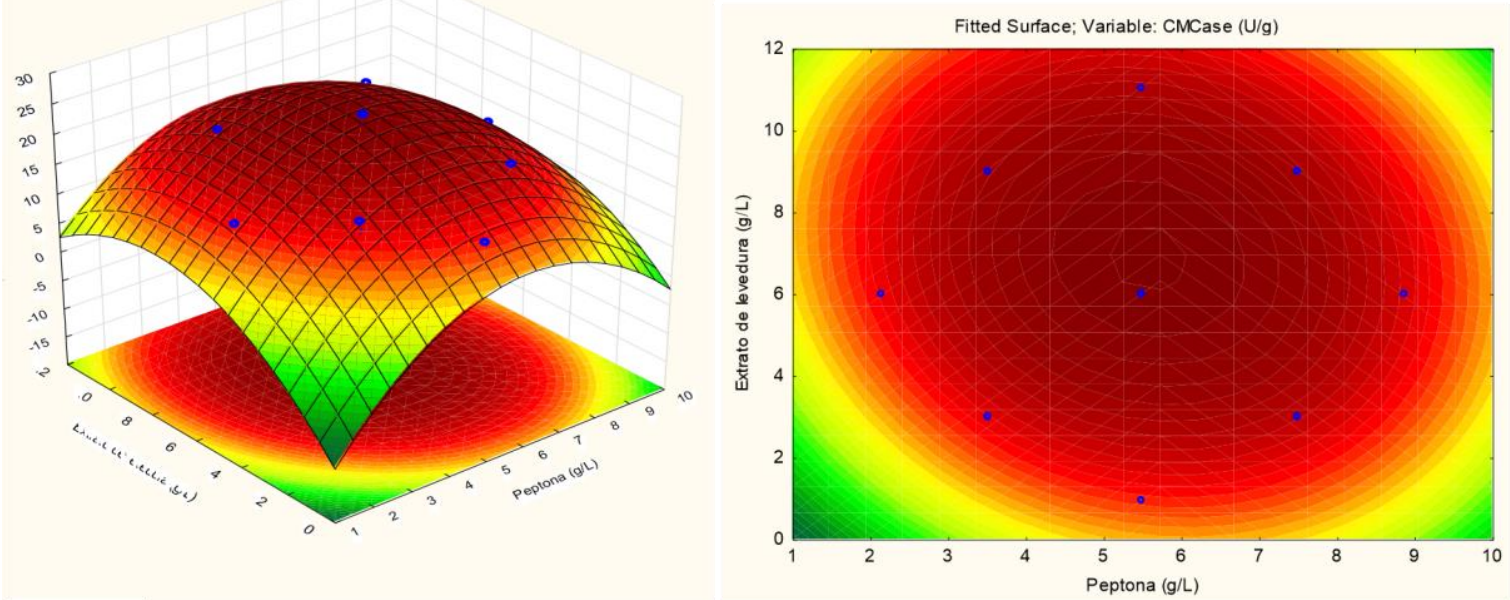

$\mathrm{C}$
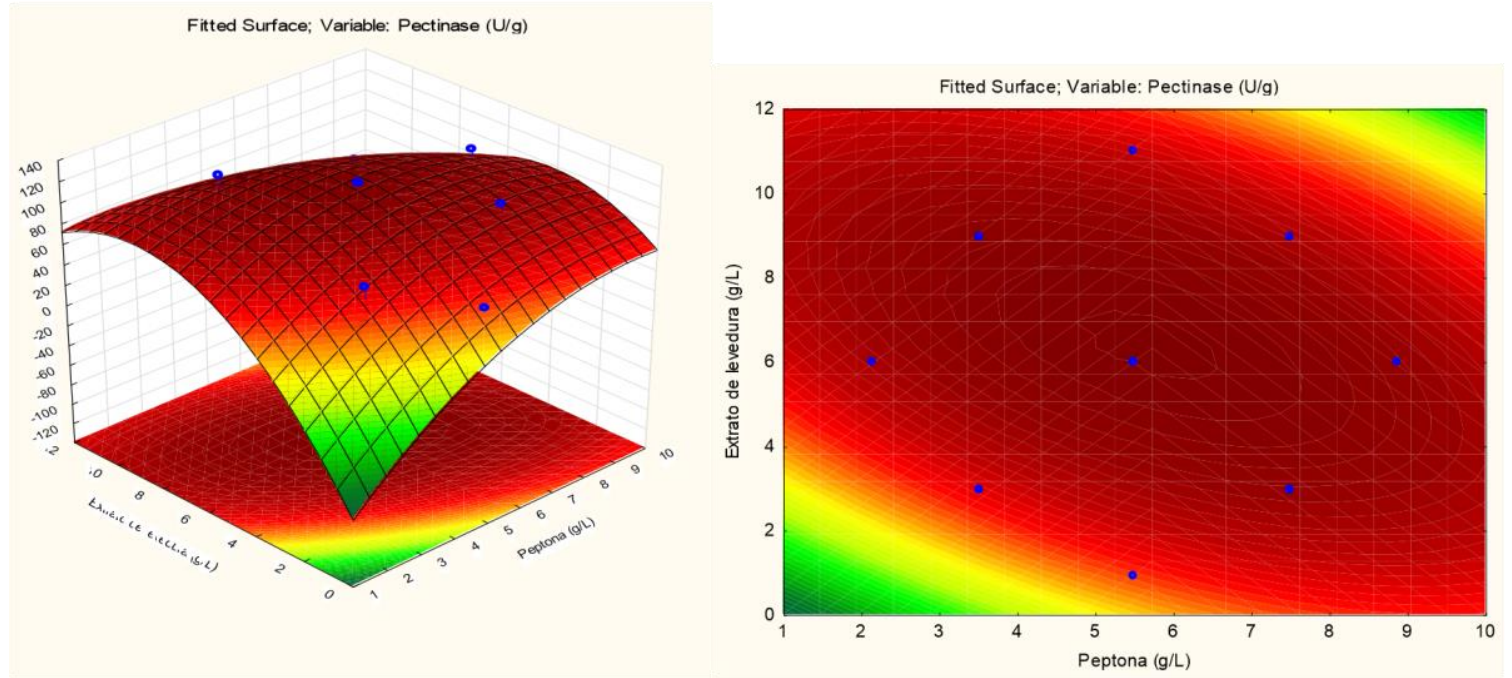

Fonte: Própria (2020). 


\section{Validação dos modelos}

Para confirmar a validade dos modelos, foi utilizado o meio sólido composto por casca de manga como principal fonte de carbono, suplementado com as concentrações otimizadas descritas anteriormente $(5,5 \mathrm{~g} / \mathrm{L}$ de peptona; $6,84 \mathrm{~g} / \mathrm{L}$ de extrato de levedura e $6,94 \mathrm{~g} / \mathrm{L}$ de pectina cítrica). As condições de temperatura, $\mathrm{pH}$, tempo de fermentação e porcentagem de umidade foram ajustadas conforme mencionado no delineamento experimental. Todas as experiências foram realizadas em triplicata.

Os valores experimentais foram $0,819 \mathrm{U} / \mathrm{g}$ para a atividade celulase total (FPase), 26,972 U/g para a atividade endoglucanase ou carboximetilcelulase (CMCase) e 129,86 U/g para a atividade da pectinase. Foi possível demostrar uma diferença positiva entre o valor previsto e o experimental de 1,3\%,7,33\% e 5,48\%, para as atividades enzimáticas FPase, CMCase e pectinase, respectivamente, verificando a validade do modelo otimizado.

Os resultados obtidos correspondentes à atividade da enzima celulase são ligeiramente superiores aos resultados encontrados por Rodríguez-Zúñiga et al., (2011), os quais relataram atividade da enzima FPase e CMCase de 0,41 U/g e 21,0 U/g, respectivamente; por outro lado, os resultados da atividade da pectinase foram inferiores aos relatados por Kumar; Sharma; Sarkar, (2011), os quais detalham atividade pectinase de 179,83 U/g, $26 \%$ a mais do que o relatado neste estudo.

\section{Conclusões}

Com base nos resultados, o uso de cascas de manga suplementadas com fontes de nitrogênio e pectina como indutor enzimático foi satisfatório para a produção de enzimas celulase e pectinase. Da mesma forma, o uso do planejamento experimental Plackett-Burman, bem como o Delineamento composto central rotacional (DCCR), foram ferramentas eficientes para otimizar as condições do meio de cultura sólido. A atividade enzimática máxima correspondente à celulase total, endoglucanase e pectinase foi de 0,819 U/g, 26,972 U/g e 129,86 U/g respectivamente, alcançada com um meio sólido composto por cascas de manga suplementadas com 5,5 g/L de peptona; $6,84 \mathrm{~g} / \mathrm{L}$ de extrato de levedura e 6,94 g/L de pectina cítrica. A conformação estrutural das cascas de manga, por sua vez, facilitou a indução de pectinases excretadas no meio de fermentação, e também favoreceu o trabalho sinérgico enzimático entre celulases e pectinases. Dessa forma, verifica-se a viabilidade de resíduos agroindustriais, como cascas de manga, para a produção de extratos enzimáticos. 
MENDOZA, S. L. Y., ALVARADO, A. P. C. E SILVA, G. M. C.

\section{Referências}

AHMED, I. et al. Bioprocessing of citrus waste peel for induced pectinase production by

Aspergillus niger; its purification and characterization. Journal of Radiation Research and Applied Sciences, Special issue on: "Current Research and Future Trends in Biotechnology for a Healthy and Green Word”. v. 9, n. 2, p. 148-154, 1 abr. 2016.

ANUÁRIO BRASILEIRO DE HORTI\&FRUTI 2019. Santa Cruz do Sul: Editora Gazeta Santa Cruz, p. 98, 2019.

BERARDINI, N. et al. Utilization of mango peels as a source of pectin and polyphenolics. Innovative Food Science \& Emerging Technologies, v. 6, n. 4, p. 442-452, dez. 2005.

COURI, S.; FARIAS, A. X. Genetic manipulation of Aspergillus niger for increased synthesis of pectinolytic enzymes. Revista de microbiologia, v. 26, n. 4, p. 314-317, 1995.

GAUTAM, S. P. et al. Optimization for the Production of Cellulase Enzyme from Municipal Solid Waste Residue by Two Novel Cellulolytic Fungi. Biotechnology Research

International, v. 2011, 23 jan. 2011.

GUPTA, V. K. et al. Fungal Enzymes for Bio-Products from Sustainable and Waste Biomass. Trends in Biochemical Sciences, v. 41, n. 7, p. 633-645, 1 jul. 2016.

INFANZÓN-RODRÍGUEZ, M. I. et al. Optimization of Cellulase Production by Aspergillus niger ITV 02 from Sweet Sorghum Bagasse in Submerged Culture Using a Box-Behnken Design. Sugar Tech, v. 22, n. 2, p. 266-273, abr. 2020.

KARLAPUDI, A. P. et al. Plackett-Burman design for screening of process components and their effects on production of lactase by newly isolated Bacillus sp. VUVD101 strain from Dairy effluent. Beni-Suef University Journal of Basic and Applied Sciences, v. 7, n. 4, p. 543-546, 1 dez. 2018.

KUMAR, S.; SHARMA, H. K.; SARKAR, B. C. Effect of substrate and fermentation conditions on pectinase and cellulase production by Aspergillus niger NCIM 548 in submerged $(\mathrm{SmF})$ and solid state fermentation (SSF). Food Science and Biotechnology, v. 20, n. 5, p. 1289, 31 out. 2011.

MOJUMDAR, A.; DEKA, J. Recycling agro-industrial waste to produce amylase and characterizing amylase-gold nanoparticle composite. International Journal of Recycling of Organic Waste in Agriculture, v. 8, n. 1, p. 263-269, 1 dez. 2019.

MOSTAFA, F.; AHMED, S.; HELMY, W. ORIGINAL ARTICLES Enzymatic Saccharification of Pretreated Lemon Peels for Fermentable Sugar Production. Journal of Applied Sciences Research, v. 9, p. 2301-2310, 1 jan. 2013.

MRUDULA, S.; MURUGAMMAL, R. Production of cellulase by Aspergillus niger under submerged and solid state fermentation using coir waste as a substrate. Brazilian Journal of Microbiology, v. 42, n. 3, p. 1119-1127, set. 2011. 
MENDOZA, S. L. Y., ALVARADO, A. P. C. E SILVA, G. M. C.

MUÑOZ, D.; PANTOJA, A. J.; CUATIN, M. F. Aprovechamiento de Residuos Agroindustriales como Biocombustible y Biorefinería. v. 12, n. 2, p. 10, 2014.

RODRÍGUEZ-ZÚÑ̃IGA, U. F. et al. Produção de celulases por Aspergillus niger por fermentação em estado sólido. Pesquisa Agropecuária Brasileira, v. 46, n. 8, p. 912-919, ago. 2011.

SADH, P. K.; DUHAN, S.; DUHAN, J. S. Agro-industrial wastes and their utilization using solid state fermentation: a review. Bioresources and Bioprocessing, v. 5, n. 1, p. 1, 2 jan. 2018.

SHAHRIARINOUR, M. et al. Effect of medium composition and cultural condition on cellulase production by Aspergillus terreus. African Journal of Biotechnology, v. 10, p. 7459 7467, 1 jul. 2011.

SHOUKRY, A.; HASSAN, F.; EL-SHALL, H. Optimization of Cellulase Enzyme Production from Pleurotus under Submerged Fermentation. 6 abr. 2019.

WOOD, T. M.; BHAT, K. M. Methods for measuring cellulase activities. In: Methods in Enzymology. Biomass Part A: Cellulose and Hemicellulose. [s.l.] Academic Press, 1988. v. 160p. 87-112. 